\title{
CAROTENOIDS AND TOCOPHEROL CONTENT OF TOMATO FRUITS AND TOMATO PRODUCTS
}

El- Dengawy, R. A. H. ${ }^{1}$; B. R. Ramadan²; Leif- A. Garbe ${ }^{3}$ and T. Kurz ${ }^{4}$

${ }^{1}$ Dept. of Food Industries, Faculty of Agric. at Damietta, Mansoura Univ., Damietta, Egypt

2 Dept. of Food Sci. \& Techn., Faculty of Agric., Assiut Univ., Assiut, Egypt

${ }^{3}$ Inst. of Biotechnology, Berlin Univ. of Technology, Berlin, Germany

${ }^{4}$ Berlin Sugar Institute, Berlin Univ. of Technology, Berlin, Germany

\begin{abstract}
The changes in the $ß$-carotene, lycopene and $\alpha$-tocopherol content of tomato as a function of varieties and processing factors were investigated. The concentration of B-carotene, lycopene and $\alpha$-tocopherol were ranged from 653.5 to $2032.1 \mu \mathrm{g} / \mathrm{l00 \textrm {g }}$, from 825.0 to $2290.5 \mu \mathrm{g} / \mathrm{l00 \textrm {g }}$ and from 43.0 to $94.8 \mu \mathrm{g} / \mathrm{l00 \textrm {g }}$ fresh weigh of ripe tomato fruits, respectively. The prepared tomato products; juice and paste contained higher amounts of lycopene (938.0- $4069.9 \mu \mathrm{g} / \mathrm{l00g})$ and $\alpha$-tocopherol $(137.0-396.0 \mu \mathrm{g} / \mathrm{l00 \textrm {g }})$ than tomato fruits for fresh consumption. Tomato juice and paste from the market contained amount of B-carotene more than that of the prepared juice and paste. Significant differences could be obtained between the examined varieties with regard to caroteniods and $\alpha$-tocopherol concentration. B-carotene was the most susceptible compound toward thermal degradation.

Keywords: Carotenoids; $\alpha$-tocopherol; tomatoes; processing.
\end{abstract}

\section{INTRODUCTION}

Tomato is an important agricultural commodity worldwide. Because of their year-round availability, tomato and tomato products merit attention, even in terms of value of micronutrients existing at low concentration. In addition to the vital carotenoids they contain considerable amounts of vitamin C and vitamin E (Abushita et al., 1997). Epidemiological studies show that the consumption of tomato and tomato-based products can help to prevent various forms of cancers, especially prostate cancer, and heart diseases (Gerster, 1997; Giovannucci, 1999; Rao and Agarwal, 2000; George et al., 2001 and Lister, 2003). Therefore recommendations have been made to increase daily intake of fruits and vegetables rich in these nutrients to lower risk of cancer and cardiovascular diseases (American Cancer Society, 1984; Steinmetz and Potter, 1991; Block et al., 1992).

In studies by Stahl and Sies (1992)), lycopene has been found more bioavailable from heat processed tomato products than that from fresh tomatoes. The reasons for this are, so far, unknown. The benefits of tomatoes and tomato products have been attributed mostly to their carotenoids content. Among carotenoids found in human serum, tomato products contribute to nine. In human diet, tomatoes and tomato products were the predominant sources of lycopene, which has been found to be available for antioxidant properties (Stahl and Sies, 1992). The second 
predominant carotenoid in tomato was lycopene epoxide, an oxidation product of lycopene. Its biological and technological role is not clarified yet, but Khachik et al. (1992) reported that epoxides of carotonoids are not present in extract from human plasma. A study by Oshima et al. (1996) showed that supplementation with such carotenoids inhibits singlet oxygenmediated oxidation of human plasma low density lipoprotein, thereby reducing the risk of cardiovascular diseases.

The aim of this work was to examine extensively the differences between three varieties of tomato fruits concerning their carotenoids and tocopherol content and to study the effect of processing on carotenoids and tocopherol content of tomato products.

\section{MATERIALS AND METHODS}

Tomato fruits: $5 \mathrm{~kg}$ of each tomato fruits of three commercial cultivars: Cherry Rispentomaten (Italy), Rispentomaten AUSD (Germany) and Cocktails Trauchtomaten (Holland) were brought from local market of Berlin City during August, 2005. Tomato juices and pastes were prepared from these fruits.

Preparation of juice and paste: Tomato fruits of each cultivar were washed, chopped, cold extracted and sieved to remove seeds and peels. The extract of each cultivar was divided into three portions. The first portion (raw tomato extract) was immediately packed in glass and analyzed freshly. The second portion was concentrated to $9 \%$ TSS (juice) by using a rotary evaporator at $60^{\circ} \mathrm{C}$ under vacuum and packaged in glass cans of $200 \mathrm{~g}$ net weight. The cans were sterilized at $100^{\circ} \mathrm{C}$ for $30 \mathrm{~min}$ and were analyzed after cooling. The third portion was concentrated to reach TSS content of $28-30 \%$ (paste) by using a rotary evaporator at $60{ }^{\circ} \mathrm{C}$ under vacuum. The paste was packaged in glass cans of $200 \mathrm{~g}$ net weight and sterilized at $100^{\circ} \mathrm{C}$ for 30 min. The cans were cooled and immediately analyzed in the laboratory of Berlin Sugar Institute, Berlin Univ. of Technology, Germany.

Tomato products from the market: The processed tomato products; juice and paste were brought from local market in Berlin City in August, 2005. Tomato juice namely "Passierte Tomaten" (TSS not more than $8 \%$ ), and tomato paste namely "Tomates Dalcasi" produced by Tat Company, TSS content $28-30 \%$. Immediately the samples were analyzed after the cans had been opened in laboratory.

Extraction of carotenoids and tocopherols: Carotenoids and tocopherols were extracted from tomatoes and its products by using the method of Abushita et al. (1997). Brown colored conical flasks, round-bottom flasks and separatory funnels were used in the different analyses to avoid light catalyzed degradation of photosensitive vitamins. Ten milliliters of homogenate sample was taken, in duplicate, and disintegrated in a crucible mortar in the presence of $1 \mathrm{~g}$ of quartz sand. Methanol was added first to catch water and make the transfer of lipophilic carotenoids and tocopherols to the less polar solvent more easy in the a sequent step. A mixture of 60:20 $(\mathrm{v} / \mathrm{v})$ carbontetrachloride - methanol containing $(0.5 \%)$ butylated 
hydroxytolueune (BHT) was added, and the mixture was shaken for 15 min. The lower colored layer was separated in a separatory funnel and dried on anhydrous sodium sulphate $\left(\mathrm{Na}_{2} \mathrm{SO}_{4}\right)$. The solvent was then evaporated under vacuum by rotary evaporator at maximum $40{ }^{\circ} \mathrm{C}$. The residues were either redissolved in an aliquot of the HPLC eluent carotenoids analysis or applied for saponification procedure for analyses of tocopherols.

Saponification of Tocophorols: To the extracted pigment and Tocopherols fraction, $5 \mathrm{ml}$ of saturated methanolic $\mathrm{KOH}, 0.5 \mathrm{~g}$ ascorbic acid, and $20 \mathrm{ml}$ of methanol were added. The mixture was then saponified by refluxing for 30 $\mathrm{min}$ at the boiling point of methanol. After cooling the flask, $15 \mathrm{ml}$ of salted water were added and the analogues of tocopherol were extracted twice with $40 \mathrm{ml}$ of analytical grade $\mathrm{n}$-hexane in a separatory funnel. The hexane fractions were collected, washed twice with distilled water, and dried on anhydrous $\mathrm{Na}_{2} \mathrm{SO}_{4}$. The solvent was evaporated under vacuum at $30{ }^{\circ} \mathrm{C}$, and the residues were redissolved in $5 \mathrm{ml}$ of HPLC-grade $\mathrm{n}$ - hexane for chromatograhic analysis. Separation conditions and parameters for the HPLC determination of carotenoids and tocopherols were applied according to methods of Biacs and Daood (1994) and Speek et al. (1985), respectively. For the identification of peaks the retention times and maximum absorption spectra of carotenoids and tocopherols were compared with those standard materials, which were also used for quantification by HPLC apparatus in Biotechnology Institute, Berlin Univ. of Technology, Berlin, Germany

Statistical analysis: Data were subjected to analysis of variance and least significant difference (LSD) at $5 \%$ probability according to Little and Hills (1978).

\section{RESULTS AND DISCUSSION}

\section{Evaluation of tomato fruits:}

B-carotene, lycopene and $\alpha$-tocopherol content of fruits of the studied tomato cultivars are shown in Table 1 . The lowest value of $B$-carotene in the studied tomato varieties was determined for the Germany cultivar (Rispentomaten AUSD), while the other cultivars recorded higher values with 2032.10 and $715.00 \mu \mathrm{g} / \mathrm{l00g}$ fresh weight for Holland (Cocktails Trauchtomaten) and Italy (Cherry Rispentomaten), respectively. With regard to lycopene content, among the examined tomato fruits, Italy cultivar contained the highest level $(2290.50 \mu \mathrm{g} / \mathrm{l00g}$ fresh weight) followed by Holland and Germany cultivars. Data in Table 1 showed that the Italy, Germany and Holland cultivars contained 94.80, 43.00 and $76.20 \mu \mathrm{g} \mathrm{a}-$ tocopherol $/ \mathrm{l} 00 \mathrm{~g}$ fresh weight, respectively. This variation may be due to the varietals, agricultural factors and the techniques for cultivation.

Table (1). B -carotene, lycopene and $\alpha$-tocopherol content $(\mu \mathrm{g} / \mathrm{l00 \textrm {g }}$ fresh weight) of tomato fruits

\begin{tabular}{|l|c|c|c|}
\hline \multirow{2}{*}{ Fruits of tomato varieties } & \multicolumn{2}{|c|}{ Carotenoids } & \multirow{\alpha}{\alpha}{$\begin{array}{c}\boldsymbol{\alpha}- \\
\text { tocopherol }\end{array}$} \\
\cline { 2 - 3 } & $\boldsymbol{\beta}$-carotene & Iycopene & 94.8 \\
Charry Rispentctomatom (Italy) & 715.00 & 2290.50 & 43.00 \\
Rispen tomatam AUSD (Germany) & 653.50 & 825.00 & 76.20 \\
Cocktails trauch tomaten (Holland) & 2032.10 & 2070.00 & \\
\hline
\end{tabular}


These results are in the range as reported by Abushita et al. (2000) for some tomatoes for fresh consumption.

\section{Evaluation of processed tomatoes}

Data in Table 2 show that the tomato juice of Germany cultivar contained the highest level of B-carotene $(470.0 \mu \mathrm{g} / \mathrm{l} 00 \mathrm{~g}$ wet weight) while, the juices, from Italy and Holland cultivars contained 2636.0 and 362.9 $\mu \mathrm{g} / \mathrm{l} 00 \mathrm{~g}$ wet weight, respectively. The lycopene contents were 2328.3, 985.0 and $938.0 \mu \mathrm{g} / \mathrm{l} 00 \mathrm{~g}$ wet weight for Italy, Germany and Holland tomato juice, respectively. In the same trend, high concentrations of lycopene have been found in different fresh and processed tomato products as reported by Klaui and Bauesrfeind, 1981; Daood et al., 1987; Tan, 1988; Tavares and Rodriquez-Amaya, 1994 and Tonucci et al., 1995. Moreover, the $\alpha$ tocopherol compound was 247.2, 137.0 and $156.0 \mu \mathrm{g} / \mathrm{l00 \textrm {g }}$ wet weight for Italy, Germany and Holland tomato juice, respectively.

Data in Table 2 also represent the content of B-carotene, lycopene and $\alpha$-tocopherol in the processed tomato paste. The concentration of B-carotene in the studied samples ranged from 185.0 to $215.0 \mu \mathrm{g} / \mathrm{l00 \textrm {g }}$ wet weight however, the levels of lycopene were ranged from 1891.93 to $4069.90 \mu \mathrm{g} /$ $100 \mathrm{~g}$ wet weight. With regard to $\alpha$-tocopherol content, the paste of Italy cultivar contained the highest level with $396.00 \mu \mathrm{g} / \mathrm{l00g}$ wet weight, followed by Germany cultivar $(308.00 \mu \mathrm{g} / 100 \mathrm{~g})$ and Holland cultivar $(243.60 \mu \mathrm{g} /$ $100 \mathrm{~g})$ fresh weight. The results indicated that the preparation of tomato products decreased the concentration of $B$-carotene. This means also that $B$ carotene is more sensitive than lycopene, and therefore, its in vitro antioxidant activity is higher in aqueous media as previously reported by Tonucci et al. (1995). Abushita et al. (2000) shows that a-tocopherol lost $20.3 \%$ of its content during thermal processing of tomato paste.

Table (2). B-carotene, lycopene and $\alpha$-tocopherol content $(\mu \mathrm{g} / \mathbf{1 0 0 g}$ fresh weight) of the processed tomato products (at the laboratory)

\begin{tabular}{|l|c|c|c|}
\hline \multirow{2}{*}{ Processed tomato products } & \multicolumn{2}{|c|}{ Carotenoids } & \multirow{2}{*}{-tocopherol } \\
\cline { 2 - 4 } & $\boldsymbol{B}$-carotene & lycopene & \\
Tomato juice from: & & & \\
Charry Rispentctomatom (Italy) & 236.00 & 2328.30 & 247.20 \\
Rispen tomatam AUSD (Germany) & 470.00 & 985.00 & 137.00 \\
Cocktails trauch tomaten (Holland) & 362.90 & 938.00 & 156.00 \\
Tomato paste from: & & & \\
Charry Rispentctomatom (Italy) & 197.50 & 4069.90 & 396.00 \\
Rispen tomatam AUSD (Germany) & 215.00 & 1891.93 & 308.00 \\
Cocktails trauch tomaten (Holland) & 185.00 & 2137.66 & 243.60 \\
\hline
\end{tabular}

The data in table 3 shows that the tomato juice from the market contained higher levels of B-carotene, lycopene and a-tocopherol than tomato paste from the same market. Generally, the processed products contained higher levels of lycopene and $\alpha$-tocopherols than tomato fruits. Data in Table 4 shows that there are high significant differences between the examined tomato varieties and during thermal processing (concentration and 
sterilization) of tomato products (juice and paste). In general, these results agree with those reported by Khachik et al. (1992); Tonucci et al. (1995) and Abushita et al. (2000).

Table (3): B-carotene, lycopene and $\alpha$-tocopherol content $(\mu \mathrm{g} / 100 \mathrm{~g}$ fresh weight) of tomato juice and paste from the market

\begin{tabular}{|l|c|c|c|}
\hline \multirow{2}{*}{ Tomato products } & \multicolumn{2}{|c|}{ Carotenoids } & \multirow{2}{*}{$\boldsymbol{\alpha}$-tocopherol } \\
\cline { 2 - 3 } & $\boldsymbol{B}$-carotene & lycopene & \\
\hline Passierte Tomaten (Juice) & 780.00 & 1866.90 & 207.60 \\
Tomatoes Dalcasi (Paste) & 539.00 & 1790.00 & 110.40 \\
\hline
\end{tabular}

Table (4): Statistical analysis of mean values of B-carotene, lycopene and $\alpha$-tocopherol of tomato fruits and tomato products $(\mu \mathrm{g} /$ $\mathrm{g}$ fresh weight)

\begin{tabular}{|c|c|c|c|c|c|}
\hline Variety & \multicolumn{2}{|c|}{\begin{tabular}{|l|l|} 
B-carotene & lycopene \\
\end{tabular}} & a-tocopherol & mean & LSD $5 \%$ \\
\hline \multicolumn{5}{|l|}{ Fresh fruit: } & \multirow{4}{*}{$0.7762^{* *}$} \\
\hline $\begin{array}{r}\text { Italy } \\
\end{array}$ & $7.15^{\mathrm{bc}}$ & $22.9^{b}$ & $0.95^{f}$ & 5.916 & \\
\hline Germany & $6.53^{c}$ & $8.25^{f}$ & $0.43^{n}$ & 4.46 & \\
\hline Holland & $20.32^{a}$ & $20.7^{c}$ & $0.76^{9}$ & 8.596 & \\
\hline mean & 11.33 & 17.28 & 0.713 & & \\
\hline \multicolumn{6}{|l|}{ Processed Juice from: } \\
\hline \begin{tabular}{|c|} 
Italy \\
\end{tabular} & $263^{\text {ef }}$ & $23.28^{b}$ & $2.47^{\mathrm{c}}$ & 28.956 & \multirow[t]{3}{*}{$0.484^{\star \star}$} \\
\hline Germany & $4.7^{d}$ & $9.83^{e}$ & $1.37^{\mathrm{e}}$ & 12.33 & \\
\hline Holland & $3.62^{\text {ole }}$ & $9.38^{\mathrm{e}}$ & $1.56^{\mathrm{d}}$ & 17.15 & \\
\hline mean & 3.65 & 14.16 & 1.8 & & \\
\hline \multicolumn{6}{|l|}{ Processed paste from: } \\
\hline Italy & $7.97^{b}$ & $10.69^{a}$ & $3.96^{\mathrm{a}}$ & 2.46 & \multirow[t]{3}{*}{$0.070^{\star \star}$} \\
\hline Germany & $2.15^{f}$ & $18.91^{d}$ & $3.08^{b}$ & 1.626 & \\
\hline Holland & $1.85^{\dagger}$ & $21.37^{c}$ & $2.43^{c}$ & 1.583 & \\
\hline mean & 3.99 & 16.99 & 3.16 & & \\
\hline LSD 5\% & $0.275^{\star \star}$ & $0.872^{\star \star}$ & $0.059^{\star \star}$ & & \\
\hline Inter LSD 5\% & $10344^{\star *}$ & $0.838^{\star \star}$ & $0.122^{\star \star}$ & & \\
\hline \multicolumn{6}{|c|}{ Tomato products from the market: } \\
\hline \begin{tabular}{|c|}
$\begin{array}{c}\text { Passierte Tomaten } \\
\text { (Juice) }\end{array}$ \\
\end{tabular} & $7.80^{\mathrm{b}}$ & $18.66^{\mathrm{a}}$ & $2.07^{d}$ & $9.51^{a}$ & \multirow[t]{3}{*}{$0.1573^{\star \star}$} \\
\hline $\begin{array}{c}\text { Tomatoes Dalcasi } \\
\text { (paste) }\end{array}$ & $5.39^{c}$ & $17.90^{\mathrm{a}}$ & $1.10^{\mathrm{d}}$ & $8.13^{b}$ & \\
\hline mean & $6.595^{b}$ & $18.28^{a}$ & $1.585^{c}$ & & \\
\hline LSD 5\% & \multicolumn{5}{|c|}{$1.439^{\star *}$} \\
\hline Inter LSD 5\% & & & NS & & \\
\hline
\end{tabular}

\section{REFERENCES}

Abushita, A. A; Hebehi, E. A.; Daood, H. G. and Biacs, P. A. (1997). Determination of antioxidant vitamins in Tomatoes. Food Chem., 60, $207-212$

Abushita, A. A.; Daood, H. G. and Biacs, P.A. (2000). Change in carotenoid and Antioxidant in Tomato as a function of varietal and technological factors. J. Agric. food Chem., 48, 2075 - 2081. 
American Cancer Society (1984). Nutrition and Cancer: caution and prevention. An American Cancer Society Special Report. C A Cancer J. Clin., 34, 5 -10.

Biacs, P.A.;and Daood, H.G. (1994). High-performance liquid chromatography with photodiode-array detection of carotenoids and carotenoid esters in fruits and vegetables. J. plant physiol., 143, $520-$ 525.

Block, G.; patterson, B.; and Subar, A. (1992). Fruits, vegetables and cancer prevention a review of the epidemiological evidence. Nutr. Cancer, 18, 1-29.

Daood, H. G.; Biacs, P. A.; Vinkler, M.; Hoschks, A. and Hajdu, F. (1987). Separation and identification of tomato fruit pigments by TLC and HPLC. Acta Aliment, 16, 339 - 350.

George, J.; Nutall, S. L. and kendall, M. J. (2001). Prostate cancer and antioxdants. J. of Clinical Pharmacy and Therapeutics, 26, 231-233.

Gerster, H. (1997). J. of American College of Nutrition, 16, 109-126.

Giovannucci, E. (1991). Tomatoes, Tomato-based products lycopene, and cancer: review of the epidemiological literature. J. of the National Cancer Institute, 91, 313-331.

Khacik, f.; Goli, M.B.; Beecher, G. R.; Holden, J.; Lusby, w.; Tenorio, M.D. and Barrera M.R (1992). Effect of food preparation on qualitative and quantitative distribution of major carotenoid constituents of tomatoes and several green vegetables. J. Agric. Food Chem., 40, 390 - 398.

Klaui, H.; Bouernfeind, J. C. (1981). Carotenoids as colors. In carotenords as colorant and vitamin A precursors; Bauer feind, J. C. Ed.; Academic press: New York, P. 48.

Lister, C. E. (2003). Antioxidants: a health revolution. New Zealand Institute for crop food Research.

Little, T. M. and Hills, F. J. (1978). Agricultural Expermintation. Johnwiley and Sons. New York.

Oshima, S.; Ojima, F. ; Sakamoto, H.; Ishiguro, Y. and Tera. J. (1996). Supplementation with carotenoids inhabits singlet oxygen-mediated oxidation of human plasma low-density lipoprotein. J. Agric. Food Chem. 44, 2306-2309.

Rao, A.V. and Agarwal, S. (2000). Role of antioxidants lycopene in cancer and heart disease. J. of American College of Nutrition , 19, 563 - 569.

Speek, A. J.; Schrijver, F. and Shreurs, H. P. (1985). Vitamin E composition of some oil as determined by HPLC with fluorometric detection. J. Food Sci., 20, $121-124$

Stahl, W. and Sies, H. (1992). Uptake of lycopene and its geometrical isomers is greated from heat-processed than from unprocessed tomato Juice in humans. J. Nut., 122, $2161-2166$.

Steinmetz, K.A.;and Potter, J.D. (1991). Vegetable, fruit and cancer. I. Epidemiology. cancer causes control, 2, 325 - 357.

Tan, N. (1988). Analytical and preparative chromatography of tomato paste carotenoids. J. Food Sci., 53, 952 - 959. 
Tavares, C.A.; and Rodriquez-Arnaya, D.B.(1994). Carotenoids composition of Brazilian tomatoes and Tomato products. Lebens. Wissen. Technol., $7,219-224$.

Tonucci, L. H.; Holden, J .M.; Beecher, G. R.; Khachik, F., Daris, C.S. and Mulokozi, G. (1995). Carotenoids content of thermally processed tomato- based products. J. Agric. Food Chem., 43, 579 - 586.

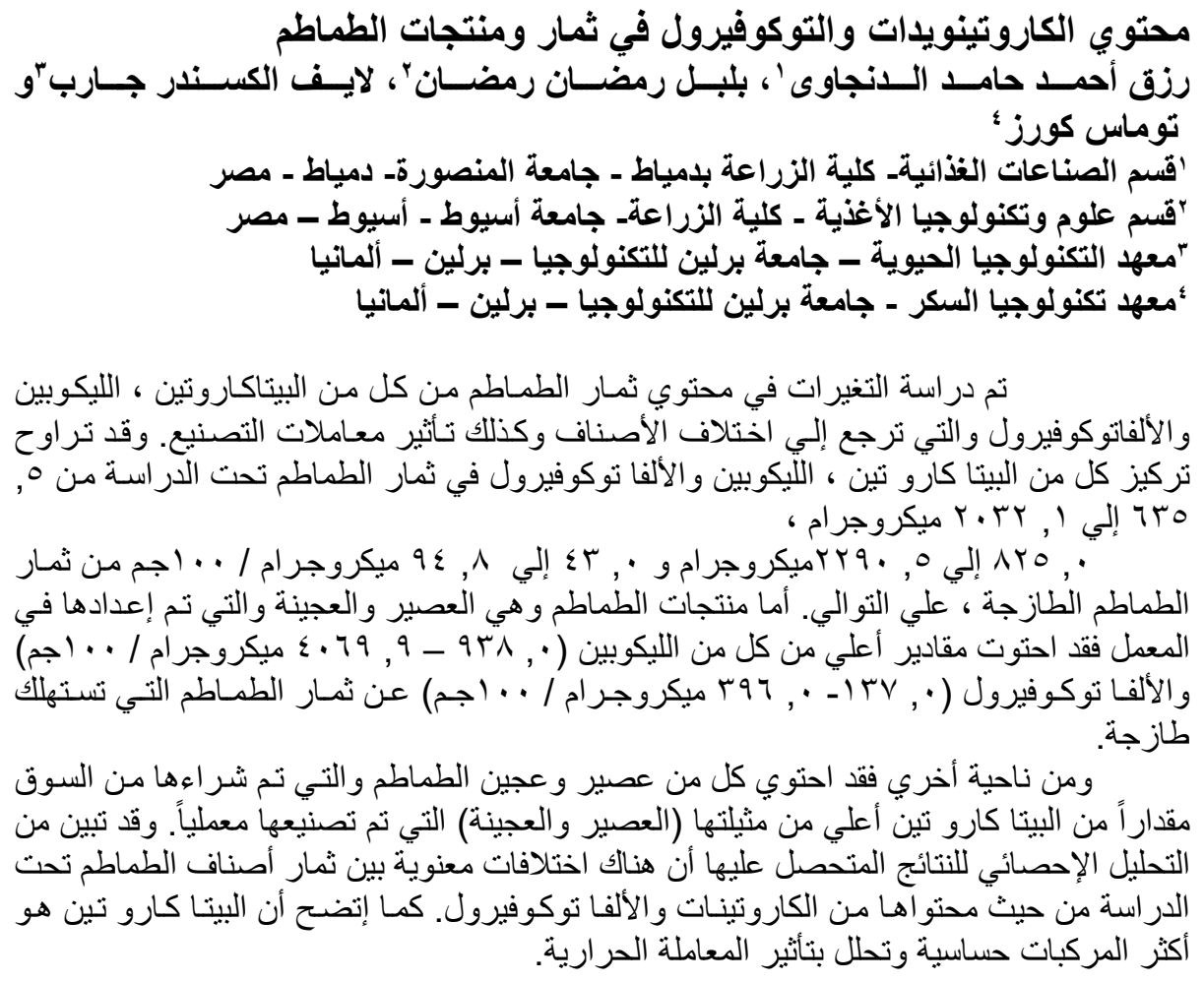

